\title{
A Sustainable Business Model Needs to be Underpinned by a Business Architecture
}

\author{
James McKee \\ Department of Information Systems, University of Wollongong (Retired), Australia
}

Copyright $(\mathcal{C} 2015$ by authors, all rights reserved. Authors agree that this article remains permanently open access under the terms of the Creative Commons Attribution License 4.0 International License

\begin{abstract}
This paper responds to the apparent contradiction between where the importance of the business model in shaping success is emphasised, "great business models can reshape industries and drive spectacular growth" [1] and the fact that many organisations either do not have a useful model or do not bring their model up to date when necessary. Problems with developing a business model will be discussed and whether model complexity may contribute to the lack of motivation in redeveloping it when required. Organization analysis has been described in many papers and books and these analyses describe the essential components of the organisation but also provide a great deal of detail which may make the business model overly complex. It is therefore sensible to separate the information that is more stable over time concerning the structure of the organisation, from the truly dynamic information affecting how the organisation perceives its approach to product and customer. This paper will suggest a systematic organisation of information to contain the more stable elements of the organisation analysis and will describe how this can provide support for a business model and make its development easier. This will also allow the model to be redeveloped as required to meet changing circumstances and therefore better able to drive business success.
\end{abstract}

Keywords Business Model, Business Architecture, Information Definition, Strategic Choices, Organisational Analysis, Business Structure, Visualisation of Architecture

\section{Introduction}

The primary aim of the research was to create a clear and well-structured information format; for business management to use to plan and manage the organisation and to make it easier to provide a more effective implementation of the required business direction. The improved format would provide a solution to the problem of overly verbose documentation that takes too long to prepare and very difficult to maintain and update. The documentation format would provide an essential transparency of the organisation's operation and intentions.

The key to good documentation is the right information in the first place and then to organise it systematically so that anyone can find what they need in order to manage the organisation correctly. The problem of communicating an organization's business intentions to the general staff of an organization is widespread and persistent, so there needs to be an effort to rethink the way this information is presented, so that it is clear, unambiguous and easy to understand. To this end we must examine what is information and to examine how the right information is collected and presented.

The importance of management information to an organisation is raised by several authors "The availability of effective management information is essential when coping with today's complexity and dynamism, both within and around organisations" ([2]). Reference [2] go on to write that "[i]nformation [t]echnology can be used to derive such information ... However the contribution of the management information generated is disappointing. Many projects do not produce the results that organisations expect". It is therefore essential to understand what information is needed to drive the organisation and not just to collect and summarise transaction data without understanding the business imperative that needs to be resolved with the right information. The business imperatives that are driving the organisation therefore also need to be well understood.

One significant problem is the definition of 'information' and the problems caused by using the term interchangeably with the term 'data', this aggravates the problem of understanding what is information? The interpretation used here is that information can be used immediately without further processing; in order to take action or make a decision. There is also the question of what is considered to be information at one level of the organisation may only be data at a more senior level. This creates a need to determine what information is required to drive the organisation effectively, and this should be declared separately at each 
major level in the organisation. This introduces the concept of the information being presented in levels of abstraction from the executive summary at the peak down to supporting detail but clearly linked through each level.

The approach taken to investigate this problem area of documentation presentation: for the business model, business organisation (architecture) and strategic plan, is covered in the next section on the research methodology. We will then look more closely at what various authors are writing about the business model then review some of the difficulties and give some discussion on how the difficulties might be resolved. Then review what an architecture would mean in a business context in the section An Example of Architecture in Commerce and finally present some thoughts on what a reference model might look like at the top level of abstraction in the section Visualising the Reference Architecture.

\section{Research Methodology}

The aim of the research was to improve the documentation of the organisational intentions using the following objectives:

1. A literature review to clarify the issues that need resolution,

2. Identify the commonly used information components that are useful.

3. Construct an information organisation to present information in a clearer way.

4. Explain how the resulting information organisation would allow for better communication of the business intentions.

The research uses the normative research methodology to provide the research framework to probe the problem area, and then to provide a structure for the solution development.

Normative research differs from an informative investigation "because the target is not only to gather information but also to point out in which aspects the object of study can be improved" ([3], p1.). In brief it encompasses the need to examine a problem area for weaknesses and investigates the possibilities for improvement. The process involves the examination of the current situation for any problems that exist and what has been done to resolve them and then to design a resolution of the identified problems. The final step is to evaluate that solution against the problem area for its effectiveness in resolving the difficulties.

The four steps of normative research are described by [3], p. 3 as:

1. Evaluative description of the initial state (defining the need for improvement)

2. Analysis of relationships and possibilities to change things

3. Synthesis: provide a proposal for improvement

\section{Evaluation of the proposal.}

Each of these steps is explained further with a brief outline of how they will be dealt with.

\subsection{Initial State}

This is a review of the literature by authors explaining why the business model is worth pursuing in the section benefits of a business model and then a look at the range of definitions that some authors have developed to try and clarify what a business model is and why it is useful in the section business model definitions.

\subsection{Possibilities for Change}

This phase explores the possibilities for change, with a review of stated problem issues in the use of business models in the section difficulties with a business model. One significant problem is the astonishing range of definitions available that encompass a huge range of business components making the model very detailed and perhaps too complex. However if the definition is made too simple then at the other end of the scale the model lacks sufficient supporting information. There is also rarely any indicators incorporated in the model that will enable managers to measure progress toward achieving the stated objectives.

\subsection{Proposal for Improvement}

The third research objective asks what would alleviate the above difficulties and determine what information components can be considered as key pieces of information that are essential for any business model and organisation plan. This is covered in the section discussion on possible improvements. It is then necessary to consider whether an organising structure can improve the presentation of information contained in various definitions of the business. The solution is to build a reference model based on the determined information elements that demonstrates a clear structure to give ease of use to the information in the section visualising the reference architecture.

\subsection{Evaluation of the Proposal}

Is the documentation more effective because it is reorganised into separate segments depending on purpose and more systematically organised so that all the staff are able to simply locate and understand the information relevant to their contribution to the achievement of the organisational direction and goals. This will be dealt with in the concluding section.

\section{Benefits of a Business Model}

The importance of the business model is becoming better understood as a tool for managers, it is particularly useful in 
order to analyse strategic choices and to set the business into a more effective direction. A good business model will focus attention on how the business is to make money, consolidate points of view of how this is to be achieved and communicate the agreed direction to the organisation. Magretta [4] states that "a business model's great strength as a planning tool is that it focuses attention on how all the elements of the system fit into a working whole" ([4], p.6).

In fact building the model may well highlight any misalignment within the organisation therefore showing where adjustments need to be made. The result could lead to the success that every company wants to achieve "great business models can reshape industries and drive spectacular growth" [1]. Reference [4] also states that "a business model tells a good story, it can be used to get everyone in the organisation aligned." Therefore "used in this way, a good business model becomes a powerful tool for improving execution" ([4], p.8).

Reference [5] also describe the business model in terms of company success "How do companies succeed? They choose an effective business model and execute it superbly" ([5], p.2). The catch is to discover how an effective model is defined and can an organisation execute it well? The next section discusses the large range of definitions available which is the correct one? To execute the model effectively everyone will need to understand the model and how it is driven, "executives can't even articulate their business models" ([5], p.2).

Reference [6] concur about the importance of the business model and state that "business models can be powerful tools for analysing, implementing and communicating strategic choices" ([6], p. 200).

Reference [7] believe that "the new business possibilities that arise as a result of the new technologies prominent among which is the internet", require an organisation to revisit existing business models and explore new challenges ([7], p. 23).

Reference [8] are also concerned that the business model is inadequately used and say there is a need for a "conceptual toolkit" to aid in the design of future business models as well as "help managers analyse and improve their current design". They believe that the business model can be represented as a series of activities and that "improved knowledge about how to describe the architecture of the activity system" will help in developing the business model ([8], p.217).

\section{Business Model Definitions}

A good business model answers the questions of who is the customer. And what does the customer value? And how does the organisation make money? [4]. But Magretta [4] is concerned about a confusion of definitions that occurs between the terms strategy and business model and make the distinction that the business model is about how the organisation works as a system and strategy is about dealing with the competition and is more about implementation.

Two definitions for a business model that cover a range of complexity are shown by [7]: they show a simple definition for a business model from Magretta [4] that the model "explains who your customers are and how you plan to make money by providing them with value" ([4]) and for a complex description, McKay and Marshall [7] describe and support the definition by Dubosson-Torbay, Osterwalder and Pigneur [9] which is very comprehensive and although it also includes customers and products it also goes on to include the 'high level architecture' of activities and processes, plus resources and capabilities, suppliers and relations and some financial aspects of transactional operations ([7], p. 25 ). However although the Magretta [4] definition is very succinct when the definition is looked at more carefully, it comprehensively covers most of the business operation as we will see in the next section.

A variety of existing definitions for business models are described by [6] (they uncovered 12 definitions used between the years 1998 - 2002) and have collated many into an evaluation table to determine what common elements are used. They have created their own definition around the most common elements as follows: the business model is "a representation of a firm's underlying core logic and strategic choices for creating and capturing value within a value network" ([6], p.202).

Their use of the term core logic is explained as defining the key assumptions about cause and effect relations and the internal consistency of strategic choices. Strategic choices are the second key term and creating and capturing value are the third and fourth terms of the model. Creating value is the way an organisation differentiates itself from the competition and capturing value is needed to generate profit from the value created.

Reference [5] refer to three aspects that are referred to as business models i.e. components of business models that only represent some part of a business model e.g. revenue model or organisational structure but these are not the whole thing. Then they refer to real thing being the operating business model which is the core logic for creating value which explains how the company makes money. They also mention the change model which explains how the organisation adapts to changing circumstances, but emphasise that only the operating model is the real business model. Their paper does cover the components of a business model and the operating business model in some depth and the material is well worth consideration [5]. It is worth noting that the core logic and value aspects also are part of the model definition given by Shafer, Smith \& Linder [6].

Reference [10] has also surveyed various definitions of the business model in order to 'synthesise' the following definition:

A business model is made up of the set of interdependent tasks and processes that an organisation performs with its key internal and relational resources and key processes in the pursuit 
of delivering superior customer value and appropriating value. ([10], p.158).

\section{Difficulties with a Business Model}

Reference [5] say that everyone talks about business models but $99 \%$ have no clear framework for describing their model" (2000, p.2). Despite the benefit that can derive from the business model there is concern that that many organisations are not taking sufficient advantage from developing a current business model. Johnson, Christensen and Kagermann [1] report on a "study that determined no more than $10 \%$ of innovation investment at global companies is focused on developing new business models". Perhaps part of the problem is that there are many definitions for what a business model represents and no agreement about which of the large range of possible business components a model must contain ([4], [6], [7]).

We gave above a quite succinct definition from Magretta [4], however a fuller definition of the business model from Magretta's [11] book What Management Is: How it works and why it's everyone's business is given below:

Similarly, new business models are all variations on the universal value chain that underlies all businesses. Broadly speaking, this chain has two parts. Part one includes all the activities associated with making something: design, the purchase of raw materials, the manufacturing or service-delivery process. Part two includes all the activities associated with selling something: finding and reaching customers, transacting a sale, distributing the product or delivering the service. [11].

As we can see from this definition it can in reality be interpreted as very complex and covers most aspects of the business operation and leads to the conclusion that the workings of the business model can be difficult for an organisation to develop and very difficult to manage if it is required to be updated on a regular basis.

Even the use of the term value chain means different things to different authors, Magretta [4] refers to value for the customer and Shafer \& Smith [6] refer to generating profit from the value created. It is possible that the value to the customer may be at times in conflict with value to the organisation.

If a definition is very comprehensive resulting in a very complex model, it will cost a great deal of time and money to develop; this effort would make organisations reluctant to update the model. On the other hand if the model does not include essential operating information then the model will not be very effective.

Research by [1] suggests there are two problems preventing effective use of a current business model; one is a lack of definition and secondly few companies understand their existing business model well enough; "the premise behind its development, its natural interdependencies, and its strengths and limitations" ([1], p. 60). Reference [4] is concerned about a confusion of definitions that occurs with business management and particularly between the terms strategy and business model.'

There is also concern over the lack of a common definition for the business model, by Sorensen [10] who promotes the combination of business model and business plan "there are no established definitions of business models in the literature today" ([10], p.155).

Much of the discussion in the paper by (Shafer et al., [6]) is about strategic choices and value statements, the key term 'core logic' is defined with a statement that it "helps articulate and make explicit key assumptions about cause and effect relationships and the internal consistency of strategic choices" ([6], p. 202). They list the four problems they perceive in the use of business models as follows:

- Flawed assumptions underlying the core logic.

- Limitations in the strategic choices considered.

- Misunderstandings about value creation and value capture.

- Flawed assumptions about the value network ([6], p.204).

The authors Shafer et al. [6] are clear though that the business model is not a strategy, and in clarifying the distinction between strategy and model they also use a building architecture metaphor with the architect discussing with a homeowner their requirements (number of stories, bedrooms etc.) and creating the overall building design which corresponds to the strategy and when the architect then prepares the detailed floor plan based on the choices made during the design phase this correspond to the business model (p.203). This metaphor leaves out the aspect of the architectural building design used by Sorensen [10], which is to evaluate and compare the structural viability of the design.

The difficulties with the business model that led to organisations not creating or updating their model, are as follows:

1. Lack of framework to describe the model.

2. Conflicting definitions.

3. Conflict in the use of the term value chain.

4. Some definitions are very complex.

Difficulties in the use of the model:

1. Flawed assumption.

2. Limitations in strategic choices.

3. Misunderstanding of value creation and capture.

4. Flawed assumptions about value network.

\section{Discussion on Possible Improvements}

Various terms have been used in the preceding sections and it is worth listing them here for consideration prior to discussing their inclusion in an information structure:

- Complexity vs lack of information

- Value network, value creation and value capture

- Customer and product 
- Strategic choices and strategy

- Core logic and organisational structure / processes

- Communication and alignment

- Assumptions, cause and effect relations,

- Interdependencies, strengths and limitations

Several authors $[5-7,9,11]$ describe a business model that effectively encompasses much of the operation of the organisation and ought to lead to a good model but it must make the business model very complex and possibly lead to organisations being reluctant to update it. The first question is how to simplify the model to make it sustainable but to also ensure the model is based on sufficient information to be viable as a management tool.

Authors [4-6,11] all have an aspect of the value chain/network/system in their definition of the business model with the view of delivering value to the customer and achieving value for the organisation. These two aims of 'value to the customer' and 'value to the organisation' may be in conflict. One way to resolve the conflict is for the architecture to reflect the value to the organisation together with related costs and the business model to identify the target customer group with their perception of value (it could on the one hand be the cheapest product available and on another the best quality available).

Magretta [4] in distinguishing between strategy and the business model states the model is about how the pieces of the business fit together, not how the competition is dealt with, and states dealing with competition is the job of strategy. Shafer et al agrees that the business model is not strategy and states that the model is used to evaluate strategic choices. A second question is how do the managers come up with strategic choices without having built the model?

These two questions may be easier to deal with if the information concerning the operation of the organisation is divided between the relatively stable operational information including its core logic of procedures, processes and resources from the more dynamic information about how the organisation does business and the way it deals with the scenarios of customer and product value networks. The stable information would obviously be derived first and if possible to identify limitations within the system, a start could be made on determining strategic options for the purposes of organisation development.

Reference [10] provides a detailed description of a business plan necessary to maximize the future development of the organisation as follows: "Its major components are a marketing plan, an organisation plan and a finance plan" and then goes on to say "the business plan consequently provides the analytical support and qualifications for the business model" ([10], p.165).

Interestingly in presenting the description of the organisation plan Sorenson [10] uses a building architecture metaphor; with the company overview as the architectural drawing of the house and the organisational structure as the interior design of a house. The advantage of the architectural plan he states is the ability to compare with other plans and house designs to evaluate the structure, form and foundations and judge if another plan is better or worse than yours ([10], P. 405). An important architectural facility not raised; is the useful ability with an architectural plan, to be able to judge the robustness of the design and the ability of a plan to show how the organisation can be safely modified with future changes.

Leading on from [10] the idea develops to separate the business model, the organizational plan and the strategic plan. With the organisational analysis structured into the organisational plan, future planning can be iterative between developing the business model and testing the strategic choices against the business model and choosing additional items for the strategic plan.

Each document should have a clear purpose and function as follows:

- The Organisation Plan lays out the information of 'what is' from the organisational analyses.

- The Strategic choice document lays out the various options for improvement,

- The Business Model sets out how the organisation is to do business; including selecting the target customer segment and deciding on the value to that segment then by parsing the strategic choices against the business model, decisions are made and choices selected for implementation - creating the strategic plan.

- The Strategic Plan is the summation of what developments the company is to pursue with the actions determined and the budgets set.

It is important that with the problem divided into different documents that the interdependencies are clearly identified and the linkages shown between the related elements, see figure 1 below.

Assumptions can be managed better if they are declared as assumptions in the model and include the rational of why they are felt to be justified at that point in time, they can then be tested against whatever the prevailing circumstances are as the situation changes.

The business model, the organizational plan and the strategic plan are all better structured and can be better understood if all interdependencies and cause and effect relations are identified and for them to include the degree of association. Similarly the strength and limitations need to be identified, measured and included. 


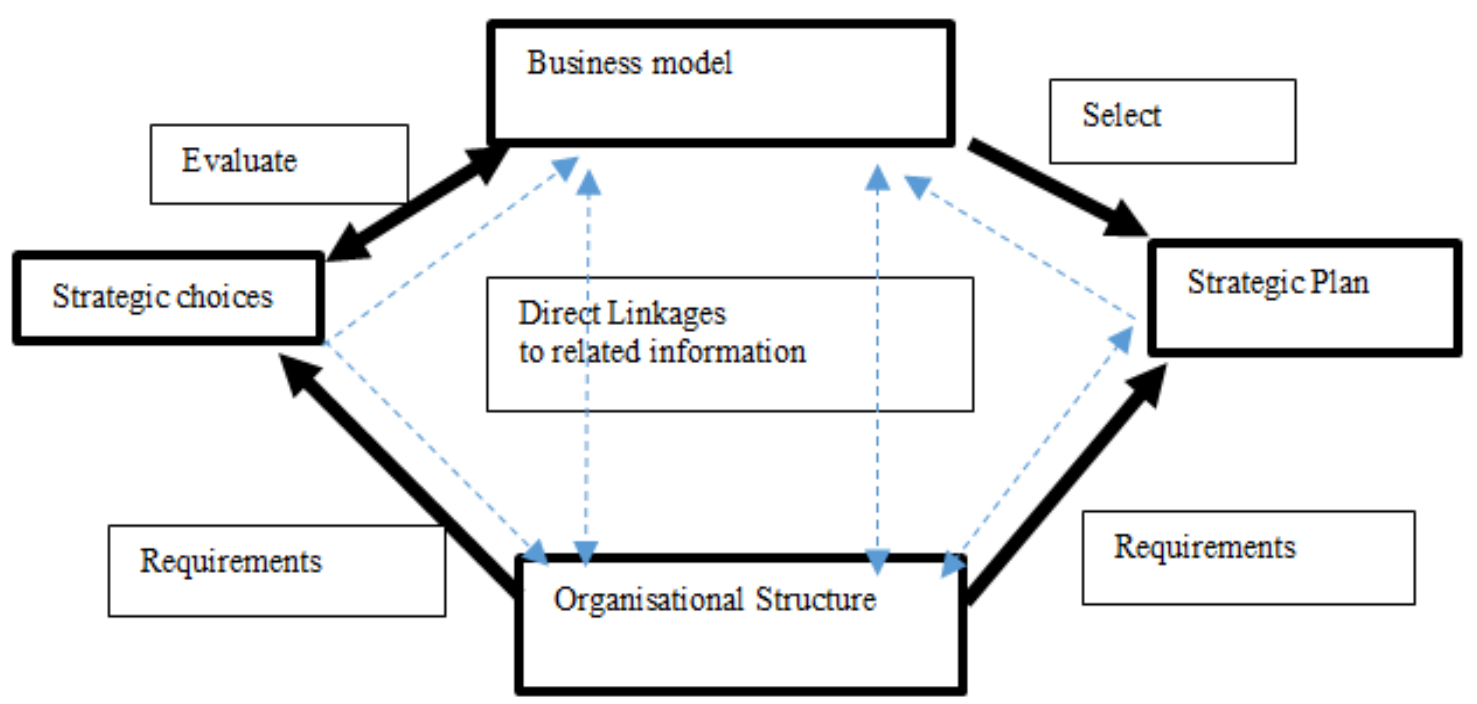

Figure 1. Development of the Business Model from the Organisational Structure

\section{Can an Information Structure Help?}

Several authors ([10], [6]) writing about the business model or business design have made use of the building architecture metaphor, I believe this points to the requirement to define what a formal business architecture would look like. There is a need to describe a business architecture that has definitions of components and suggestions for the format $\&$ structure that will provide an underpinning for the business model. This would remove many complexities from the model and make the model easier to validate, discuss and implement.

We have said above that the answer is to separate the information that is more stable over time concerning the structure of the organisation, from the truly dynamic information affecting how the organisation perceives its approach to product and customer. The method for this separation suggested here is to set out a systematic framework to encapsulate the various analyses of the business organisation in a systematic formal structure [the business architecture (BA)]. This structure would contain the more stable organisational information which would provide a foundation for the business model (BM) of how the organisation is to approach product development and marketing. Having a framework will allow a solution to be built up over time and by different people if required and also allow a check that the components within the analyses are aligned correctly with each other. When the architecture has been completed with sufficient information then this information can be used to derive the business model making the BM easier to create and modify.

What advantages does the use of architecture bring to any problem? This is partly described by the idea of having the components of a problem defined and then shown in relation to each other with the nature of their interaction explained. Bass and Clements (1998) in differentiating between design and architecture do so with the idea that design is about the function of the system but architecture goes further with the idea of envisioning the central function looking for those influences that persist beyond the current requirements, in an endeavour to improve the sustainability of the system. That is a requirement to give longevity to a solution by having the means to check the stability of changes to the system.

Underlying the definition of the business model (how the organization is to create and keep value), there must be the business structure that supports the activities to create value, i.e. the business plan comprising the finance, marketing and organisational plan [10].

Reference 13] define nine points for consideration in the 'well-designed organisation' the first is concerned with strategy, by needing to carefully define the market segments of interest to your organisation. The other considerations are about strengths and weaknesses of the organisational staff, constraints that may apply to the organisation, and coordination and communication within the organisation, (in other words the SWOT analysis). The latter covers several areas of activity including reviewing the number of organizational hierarchy levels, the controls and accountability, ensuring adaptability to change and taking into account if there are specialist cultures with staff or customers to be considered. Apart from the marketing points which belongs to the strategic plan the others could be considered part of the architectural design of the organisation.

A number of authors including [14 - 16]) are writing about business architecture as a fundamental part of enterprise architecture. Enterprise architecture (EA) was first developed to enable the IT world to better understand the business enterprise and therefore create IT systems better aligned to the business needs. Unfortunately there is still a leaning toward IT with the enterprise architecture definitions, which is certainly the case with TOGAF9 which is a well promoted EA definition.

Reference [16] make a determined effort to avoid this trap and rail against "traditional IT architecture for their remoteness from the reality of business" ([16], Kindle locn, 30), they write that EA is "these two concepts: business 
process integration and business process standardization" but then they go on to write "the top performing firms create a stable base - they digitize their core processes and embed these processes into a foundation for execution" ([16], Kindle locn. 40), that EA is a business issue but based on a digital core.

I believe that the business architecture showing the high level critical structure of the organisation including value chain, finance, logistics supply chain etc. needs to be developed first and for the IT aspect to be only included as one of the resources of the business. If appropriate, the IT component of the architecture can be developed later to take a fuller role as a value driver within the business architecture.

\section{An Example of Architecture in Commerce}

The architectural principles selected from various definitions in IT architecture for use in shaping the architecture for the strategic plan by McKee [17] were:

- A formal detailed plan to guide implementation.

- The plan should contain the components, their description and structure.

- The plan should define the inter-relationships between components.

- The plan includes guidelines covering evolution over time (the rationale for why major components are there).

- Should note environmental factors that surround the objective.

- The plan should have several levels of abstraction to allow development of ideas at the top level free from constraints of how things are to be done at the lower level.

- The plan should have a modular format that allows each level to be dealt with independently ([17], p. 209).

These principles were used in conjunction with a review of the planning literature to select the relevant critical components of strategic planning then the most appropriate relationships between them were determined. These investigations allowed the development of the following example of the second level architecture for the strategic plan [17] as shown in figure 2 below. The first level showed the focus areas and objectives for each area and the third level focused on the key performance indicators for each critical success factor (CSF).

The key principles that initiate the investigation into an appropriate architecture are those concerning components of the problem area and their inter-dependencies. The requirement of any problem analysis is to find the key components relevant to the problem area (for a business architecture the problem area will be "what is the real business value based on the operation of the organisation") and then to determine the effective cause and effect relationships and the degree of dependence between the components.

The architectural approach in many ways enhances the standard useful investigative questions of What, How, When and Why. For a business architecture it may be useful to reframe the questions in architectural terms to ask what is the core function of the organisation, what are the foundations, what are the overheads that require supporting and why are they required, how do the supporting structures operate and what are the primary organisational flows of the business etc.

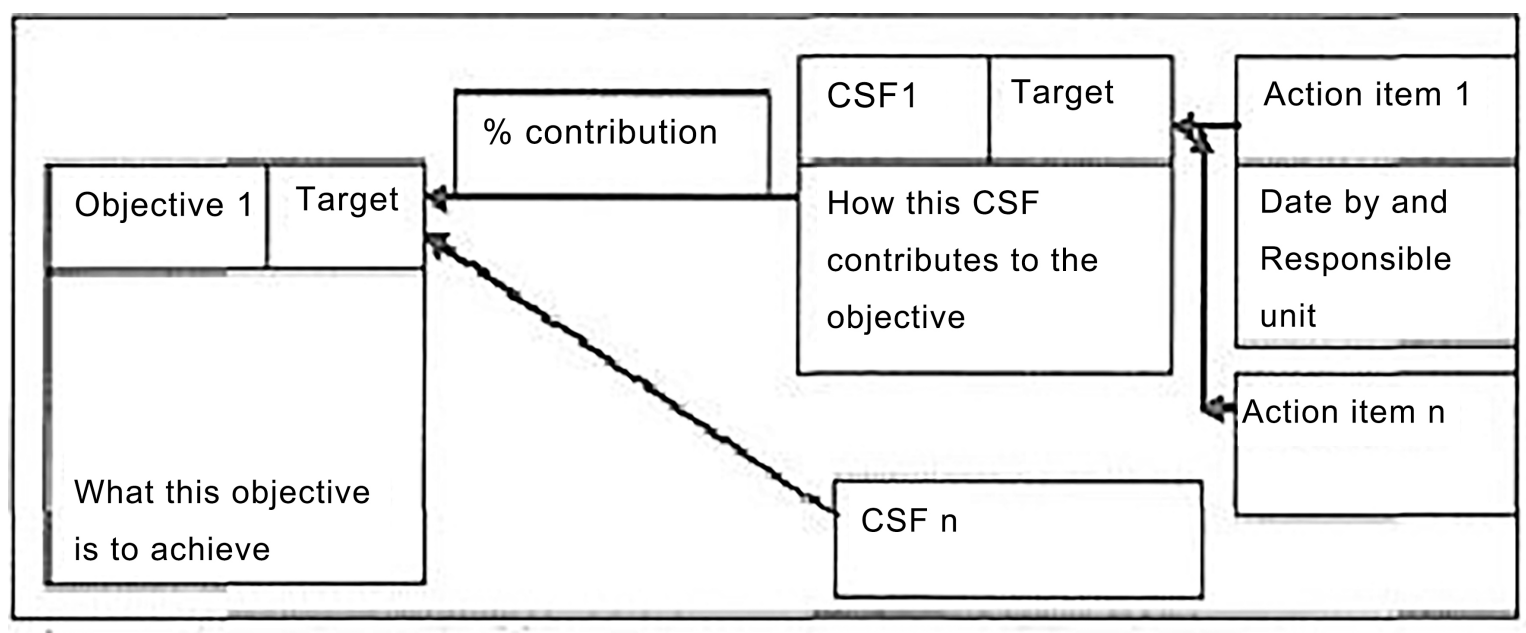

Figure 2. The Second Level of the Strategic Plan Architecture showing Objective to CSF relationship [17, p.182] 
The business architecture will be more involved than the above strategic plan example and needs to include all the key elements of the business. Like a building architecture it will require a number of different views covering different levels of detail with each level explicitly linked to adjoining levels. The concept is to give the plan a more rigorous and systematic structure that enables the plan to be easily understood by those that need to work with it. This would also enable the plan to be more easily compared with alternative plans and even with benchmark plans within the industry.

Several authors make a strong point about the need to show the critical interaction of collaborating activities, and this may be the singular critical issue of a given architecture, but few authors show any detail of how this is to be accomplished. Reference [18] emphasizes the need for linkages in his description of the value chain and in [19] they also discuss the importance of showing the essential linkages in the value chain and say the linkage should be indicated with a dash line. One should ask 'how much more power would the linkage have, if the nature of the relationship and the degree of association was also defined. An important issue is therefore to determine the nature of the interdependencies that effectively show the critical cause and effect relations that affect the performance of the organisation; in particular what figures (ratios) might highlight imbalances that need correcting to gain optimal performance.

The various forms of business analysis can point to the component of the organisation that should form the architectural structure of the organisation and separately build into the business model the decision elements of how the organisation should operate. McKee [20] describes the investigative process as follows:

The idea is to create a LOGICAL view of the problem and solution constituents that is without any preconceived notions of what the solution is or of how it is to be implemented. When the investigation is complete then the structure of information can be reconsidered for relevance and importance. From the key information elements various alternative options can be drawn up for final consideration. The solution space should now contain a range of alternative options not constrained by the PHYSICAL constraints of how they are to be implemented [20].

The business model can then draw on the support and background of the business architecture for making decisions about product and the approach to customers. A look at some of the business analysis techniques identifies many business components.

Porter's five forces are focused on the supplier, the customer and the product. Porter's value chain is about activities that add value to the product and is largely represented by the organisational processes such as logistics, marketing and sales, operations, HR, procurement etc. Reference [13] consider the need to identify constraints (the strengths and weaknesses) of the organisation e.g. the SWOT analysis which takes a look at some functions of the organisation to highlight where action or at least some explanatory comment might be useful. An analysis technique that would be useful to this process is an old one sometimes called the swim lane analysis of the process flow ( originally designed to show the flow across various departments), it could also be used to indicate which are IT processes and which are manual and importantly to highlight the value add for each unit. The various analyses would perhaps throw up key areas of value add that would become elements of the top level summary but also might show up weaknesses that might need to be addressed by strategic changes.

The PESTLE analysis will provide a final input by indicating any sort of environmental factors surrounding the organisation that may have a bearing on future decisions.

Reference [21] links the business architecture to the enterprise architecture as follows "It has been widely acknowledged that an integral part of the overall enterprise architecture .... Is represented by the business architecture. Simon[17] quotes from Gharajedaghi (2011) that business architecture can be considered 'a general description of a system. It identifies its purpose, vital functions active elements, and critical processes and defines the nature of the interaction between them".

The definition goes on to quote [22] that the business architecture is used to align strategic objectives and tactical demands, however this paper promotes the idea that the strategic plan requires its own information architecture [17]. That is not to say that the business architecture as defined above could not be used to help with the determination of what the strategic objectives need to be.

Another definition of business architecture is given by [23] "business architecture is a blueprint of the enterprise that provides a common understanding of the organization and is used to align strategic objectives and tactical demands [22]. It is an abstract set of standardized perspectives that represent a given business ecosystem. The foundational perspectives include the following core "domain" categories:

- What a business does (capability)

- The vocabulary it uses (information)

- How a business is organized (organization)

- How a business delivers value to key stakeholders (value stream) [23].

\section{Visualising the Reference Architecture}

There may be a difficulty in the amount of information required to describe an organization and its various aspects of finance, staffing, marketing etc. The answer is that the documentation has to have a well understood structure, using a cascading hierarchy of explanation and expanding level of detailed description, which will allow the right amount of focus to facilitate the development of strategic choices or used to determine the business model and how the business 
will operate.

The result of the various business analyses can be a daunting amount of information, Robert Horne suggests representing complex information - rather than with large volumes of narrative - to do so with more visual documentation and states "Highly visual 'cognitive maps' will facilitate the management and navigation through major public policy issues" [24]. A number of examples that Horne [24] has developed, show a top level of highly summarized information with clarifying images and symbols, such that any segment can be drilled down to show the supporting detail.

The analytic tools to describe a business already exist; what managers need, is to have a framework to allow them to set their results into a structure (architecture) such that they each assist and support the other. The structure will show how the results can feed into the BM so that the development of the BM can focus more specifically on how more value is to be created and retained. The aim is to make the whole process easier and more sustainable, and to allow the work to be done in a collaborative and supportive manner.

Reference [25] discuss the importance of information visualisation and the ability to "display structural relations and context that would be more difficult to detect by individual retrieval" ([25], p. 523). For a business architecture there is a need for a diagram to represent the top layer of the hierarchy showing the highest level of abstraction. Reference [26] developed the work system framework (WSF) see figure 3, which shows the various contributing components of an organization and their interrelationships directed toward the product and the customer. The WSF was meant as a means of analysis for developing the information system; however it can as easily form the basis of the business analysis as a precursor to developing the business model. The components mentioned above in Porter's five forces and the value chain analysis can be seen represented in the WSF. Alter [26] states that the "work system is a natural unit of analysis for thinking about systems in organizations. In organizational settings, work is the application of human, informational, physical, and other resources to produce products/services" ([26], p.75).

The WSF is defined by [26] as follows "The work system framework (Figure [3]) is a pictorial representation of a work system in terms of nine elements included in a basic understanding of the work system's form, function, and environment during a period when it is relatively stable" ([26], p.77). In other words it is a snapshot of the system at a point in time. It also has the advantage that it can be used to analyse the organization from a variety of levels; from the whole organization down to one department or one work unit. At the macro level it can represent either one business line of operation or the conglomerate operation as applicable. Alter further defines the internal operation as "The arrows inside the work system framework say that the specific elements of a work system should be in alignment. For example, the knowledge, skills, interests, and motivation of the participants should fit with the processes and activities in the work system" ([26], p.79). Each component should be fully supported by its alignment partners but not wastefully so. If one component is responsible for generating $10 \%$ of the added value to the product BUT it requires $50 \%$ of the costs, then it should be carefully analysed to check if this is a supportable situation.

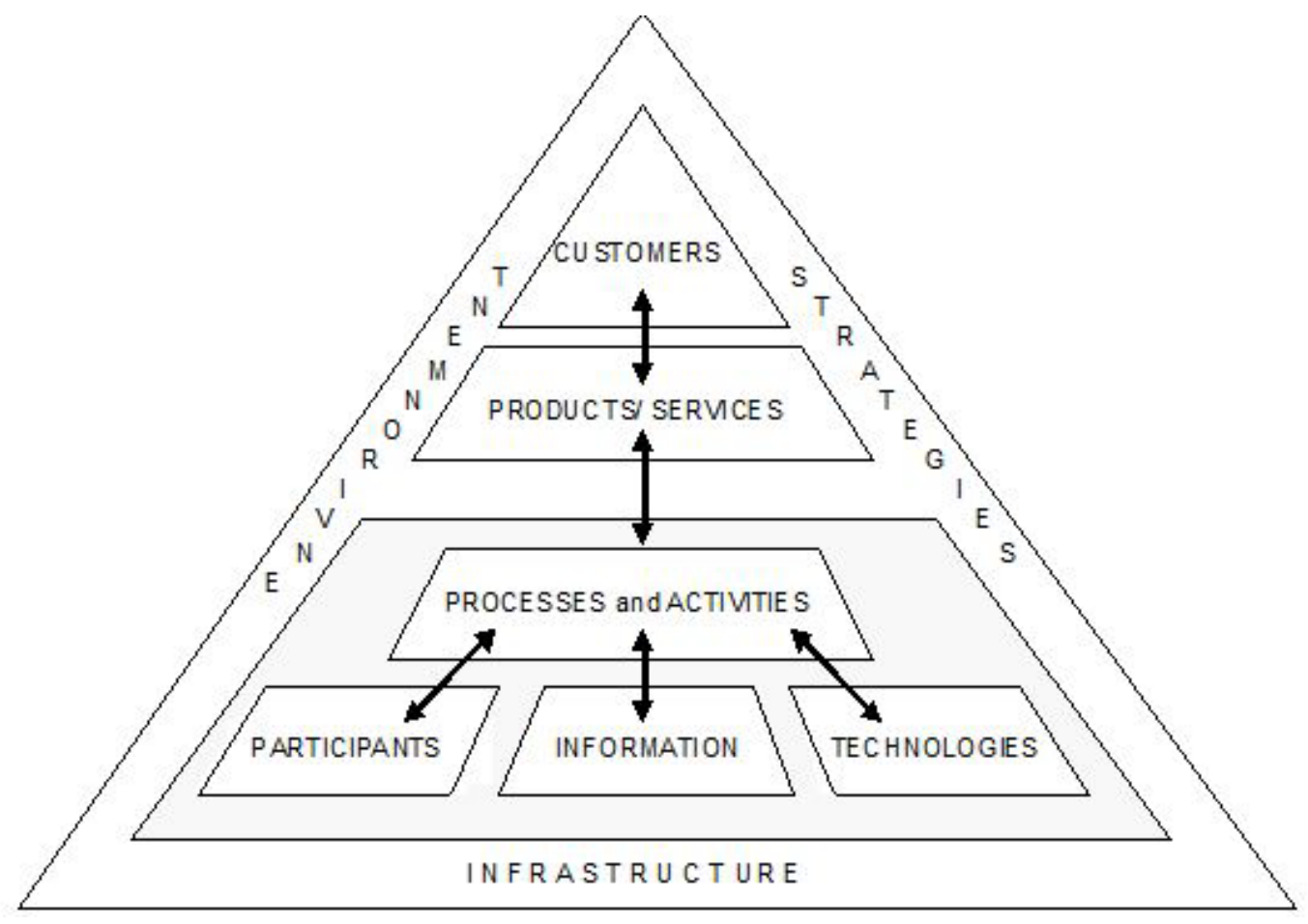

Figure 3. The Work System Framework [23] 
This framework can be expanded to include more of the various business analyses and also incorporate the definitive cause and effect relations and degree of effect which will give a picture of the major influencing activities on the operation of the organisation. These elements can then be fed into the business model development allowing focus on the chosen factors that are expected to most affect and increase profitability. The concept is to have a summary level at the top of the hierarchy that shows the critical elements for understanding the relative position and performance of the major components of the organisation. This summarisation can enable and drive discussion on strategies for future development and lead to the new business model to shape the continuing progress of the organisation. This top level would of course have explicit drill down features to directly link to supporting detail for clarification where needed.

Remembering that every organisation would have different priorities and requirements that would determine which elements, relations and ratios that are most important to it. A possible reference framework (based on the Alter [26] WSF and the analyses already discussed) might take the following form.

- The Product element would describe the main product line with the Customer element indicating the significant customer group for that product line. If there are completely disparate product lines with totally different organisation supporting them, then each such product line would require different triangle of analysis. The input into the customer and product elements would be Porter's 5 forces analysis to indicate the level of financial activity and the organisation's position within the market place.

- The infrastructure should be part of the main triangle.

- If there is a significant manufacturing production aspect of the operation then the processes, participants, information and technologies should be divided to show the proportion between the production and administration aspects. As these elements form the value chain then each element should show the value contribution of each. It may also be useful that those elements that contribute the greatest proportion of cost should be so indicated as there may be room for cost improvement.

- The SWOT analysis should take place after the five forces analysis which allows the opportunity / threat aspects of the analysis can be superimposed where required on the five forces results. The strength / weakness evaluation can also be imposed where applicable on the respective component.

- The Environment issues are tackled by the PESTLE analysis and items of potential impact should be listed against the appropriate organisational element with a grading of high, medium, or low impact and the likelihood of occurrence.

- The top level diagram merely lists those items that are most likely to be of high impact.

- The drill down document would contain the other items with a more detailed explanation.

- The decisions on the way to do business with the customer and the product focus to use are contained in the business model. The business model would use the information in the triangle to determine which strategies to choose and reasons for selection. The reference model outline for the top level of the information hierarchy might look as follows in figure 3 . Remembering that the reference model will show most kinds of activity however an organisation would only choose to show those activities that are of key relevance to their operation.

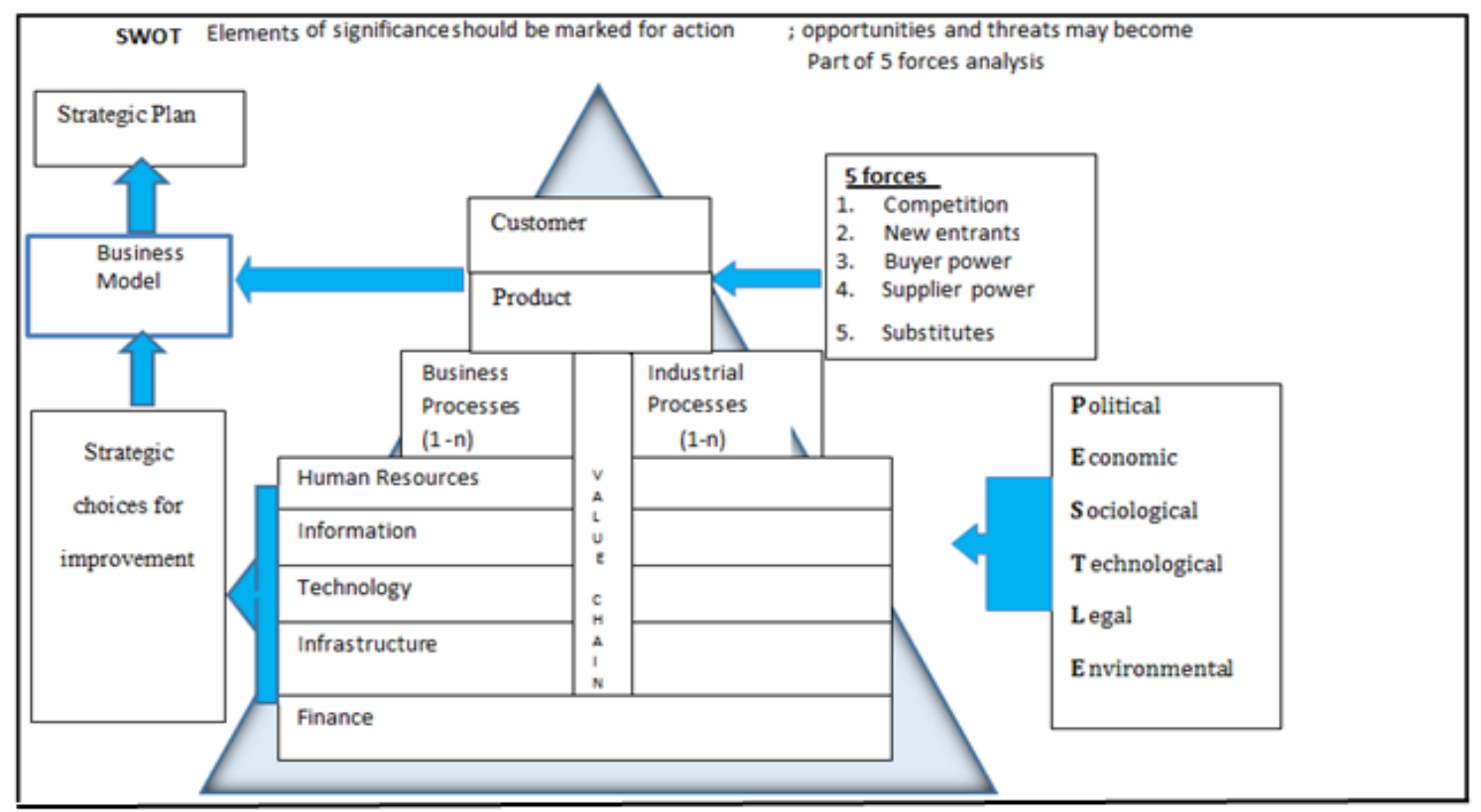

Figure 4. A Possible Reference Business Architecture 


\section{Conclusions}

This paper has proposed separating the information about the organisation into three documents, each with a specific function where the function of the business model is limited to defining how the organisation is to operate: between the customer, value to the customer and the product. This definition of the model limits the first four difficulties on creating the model raised in the earlier section on difficulties. By including any assumptions and the rationale for decisions into the model will limit the effect of the second four difficulties raised on using the model. Reducing the number of elements required in the business model will help to clarify the model definition and concentrate the model on the significant task of determining how best to achieve value to the customer and 'value add' to the organisation with the aim of improving the future performance of the organisation.

Separating information presentation between the business architecture and the business model will allow better focus and allow more frequent review and updating of the business model. This will allow the model to meet changing market demands and by explicitly including assumptions it becomes easier to check its viability against any new conditions. By also having a separate document of strategic choices and one for the strategic plan and incorporating all four documents into a single cohesive plan of the organisation allocates a specific function to each and alleviates the possibility of confusion of definition between each.

A systematic structure for the information elements resulting from the organisation analysis, particularly if significant cause and effect relations are indicated, will become a essential part of the supporting architecture. This can then be used to determine the organisation's underlying viability and enable management to make decisions on any required structural improvements.

If an organisation develops its own reference model for the structure and contents of the organisational description document (the business architecture), then as organisational analysis proceeds, so the information can be slotted into the predetermined structure, allowing the document to be developed over time and by different members of the organisation as appropriate.

Having a reference format for the organisation to use and using visualisation techniques for presenting the information the architecture will allow better communication to all staff needed to assess the real business performance and allow members of staff working on the document to be able to interpret and analyse the developing overview of the organisation.

When the architecture is sufficiently developed then a first pass on developing strategies for organisational improvement can be started. This work will have the effect of reducing the number of components and issues to be dealt with by the business model. Any strategies developed at this phase can be incorporated into the decision making and evaluated against other value adding strategies during final development of the business model. "Achieving a sustainable value proposition means investing in establishing a robust business architecture practice" ([27], p.5).

Where there is a business architecture, it becomes easy to build a portfolio of projects or initiatives that will help the business move forward in a strategic way, with each initiative bringing the business closer to the envisioned end state of the roadmap" ([28], p8).

This paper has focused on the separation of business information into the business model, the business architecture and the strategic plan to give clarity and simplicity of definition to the business model. To this end only the summary level of the business architecture was described emphasizing the cause and effect relations between each of the documents. Future research should delve deeper into the business architecture to show how the supporting detail is organized and linked to the summary. In effect there should be separate architectures for finance (not the balance sheet) but showing where costs are expended \& direct earnings are made, logistics (rather like the IT network architecture), human resources (which would include intellectual property and competencies) and of course the organizational processes. The process architecture should be the overall process flows not just IT and should delineate between the manual elements, the IT and the mechanised elements, with costs and time associated clearly attributed; a swim lane diagram that also shows the responsible departments would be very useful.

\section{REFERENCES}

[1] Johnson, M. W., Christensen, C. M. and Kagerman, H. (2008). "Reinventing Your Business Model." Harvard Business Review.

[2] Lohman, F. A. B.,Sol, H. G., \& de Vreede, G. (2003). The Illusion of Effective Management Information. International Journal of Technology, policy and Management, 3(3/4).

[3] Routio, p. (2005). Arteology: Normative Study. Retrieved $22 / 11 / 2005$.

From http://www2.uiah.fi/projects/metodi/178.htm

[4] Magretta, J. (2002). "Why Business Models Matter." Harvard Business Review: 3-8.

[5] Linder, J., \& Cantrell, S. (2000). Changing Business Models: Surveying the Landscape. Accenture Institute for Strategic Change.

[6] Shafer, S. M., Smith, H. J., \& Linder, J. C. (2004). "The power of business models." Business Horizons 48: 199-207.

[7] McKay, J., \& Marshal, P. (2004). Strategic Management of $\mathrm{e}=$ Business. Milton, John Wiley.

[8] Zott, C., \& Amit, R. (2010). "Business Model Design: An Activity System Perspective." Long Range Planning 43: 216-226. 
[9] Dubosson-Torbay, M., Osterwalder, A., \& Pigneur, Y. (2002). "E-business model design, classification and measurement." Thunderbird International Business Review 44(1): 5-23.

[10] Sorensen, H. E. (2012). Business Development: A market oriented perspective, Wiley.

[11] Magretta, J. (2003) "What Management Is: How it works and why it's everyone's business"

[12] Bass, L., Clements, P., \& Kazman, R. (1998). Software Architecture in Practice, Addison-Wesley.

[13] Goold, M., \& Campbell, A. (2002). "Do You Have a Well-Designed Organization." Harvard Business Review.

[14] Grigoriu, A. "Enterprise Architecture Matters." Retrieved 27/08, 2013, from www.enterprise-architecture-matters.co.u k/ea-links.

[15] Seref, G. B. (2012). Launching an Enterprise Architecture Practise, eBook from Amazon.Com.

[16] Ross, J. W., Weill, P., \& Robertson, D. C. (2006). Enterprise Architecture as Strategy: Creating a Foundation for Business Execution, Harvard Business School Press.

[17] McKee, J. (2013). Applying Principles from IT Architecture to Strategic Business Planning. Hershey PA, IGI Global.

[18] Porter, M. E. (1985). Competitive Advantage: Creating and Sustaining Superior Performance. The Free Press: A Division of Macmillan Inc.

[19] Porter, M. E., \& Millar, V. E, (1985). "How Information Gives You Competitive Advantage." Harvard Business Review: 1-13.
[20] McKee, J. (2015). Architecture as a Problem Solving Tool. Encyclopedia of Information Science and Technology, . M. Khosrow-Pour, IGI Global: 75-84.

[21] Simon, D. (2015). Introduction: Demystifying Business Architecture. Business Architecture management. 1-17. Springer International Publishing.

[22] Business Architecture Guild, A Guide to the Business Architecture Body of Knowledge ${ }^{\mathrm{TM}}$ (BIZBOK® Guide), Version 4.1. Part 1. 2014.

[23] Ulrich, W. \& Kuehn, W. (2015) Business Architecture Setting the Record Straight http://www.businessarchitectureassociates.com

[24] Horn, R. E. (2001). Visual Language and Converging Technologies in the Next 10-15 years (and Beyond). National Science Foundation Conference on Converging Technologies (Nano-Bio-Info-Cogno) for Improving Human Performance.

[25] Robertson, G. G., Card, S. K., \& Mackinlay, J. D. (1999). Information Visualisation Using 3D Interactive Animation. Readings in Information Visualisation: Using Vision to Think. San Francisco, Morgan Kaufmann Publishers Inc.

[26] Alter, S. (2013). "Work System Theory: Overview of Core Concepts, Extensions, and Challenges for the Future." Journal of the Association for Information Systems 14(2): 72-121.

[27] Meaden, G., \& Whelan, J. (2012). Business Architecture: A Practical Guide. Farnam GBR Ashgate Publishing ltd.

[28] Reynolds, Chris. (2009). Introduction to Business Architecture. Boston, MA, USA: Course Technology / Cengage Learning. ProQuest ebrary. Web. 23 August 2015. 